\title{
Surto de varicela em creches e escolas da Direção Regional de Saúde XXII, junho de 2005
}

\author{
Varicella outbreak among childcare and schoolchildren of 22th Regional \\ Health Division, June 2005
}

Divisão de Doenças de Transmissão Respiratória. Centro de Vigilância Epidemiológica "Professor Alexandre Vranjac". Coordenadoria de Controle de Doenças. Secretaria de Estado da Saúde de São

Paulo. EPISUS-SES/SP

\begin{abstract}
A varicela é uma infecção viral de transmissão direta e distribuição universal. Ela tem sido considerada uma doença que virtualmente infecta quase todas as pessoas que chegam à idade adulta. Em geral, a varicela é uma doença benigna quando ocorre em crianças saudáveis. A infecção é associada a risco de complicações sérias, incluindo morte, principalmente quando afeta pacientes imunocomprometidos, recém-nascidos, mulheres grávidas e adultos normais, especialmente os fumantes, que apresentam risco elevado de pneumonia.
\end{abstract}

Em climas temperados, a varicela é uma doença de escolares e pré-escolares, sendo que a maioria dos casos ocorre no inverno e primavera. A idade média de aquisição da varicela apresentou uma mudança para crianças mais jovens nos anos 90 , paralelamente ao aumento do número de crianças de menor idade ingressando em pré-escolas e creches. Atualmente, a grande maioria das crianças adquire varicela durante a pré-escola ou nos primeiros dois anos de vida escolar. Nos Estados Unidos e Reino Unido, há evidências epidemiológicas recentes que sugerem mudança na distribuição etária dos casos de varicela para idades mais altas, provavelmente resultante da imigração para estes países de adultos suscetíveis ao vírus varicelazoster (VVZ), vindos de localidades tropicais, onde é mais alta a idade da primeira infecção.

A disseminação do vírus varicela-zoster ocorre através da liberação de aerossóis respiratórios, do mesmo modo que em outras doenças exantemáticas da infância, podendo ser transmitida antes do aparecimento das lesões de pele. A transmissão também acontece através de secreções nasofaringeanas ou de lesões cutâneas ou, ainda, pelo contacto direto com as lesões, tanto de pacientes com varicela quanto com herpes-zoster. O primeiro dia de infecção pelo vírus raramente é reconhecido pelo hospedeiro humano. $\mathrm{O}$ período de incubação independe da exposição, variando de 10 a 21 dias. Os pacientes com varicela são considerados infectantes desde 24 a 48 horas antes dos sintomas nos últimos dias do período de incubação, até 4 a 5 dias após aparecimento do exantema ou completa formação das crostas. A infectividade do herpes-zoster também ocorre pelo trato respiratório, apesar do período de contágio ser menor, de aproximadamente dois dias. Assim como outros herpesvírus, o VVZ persiste em uma fase latente e ao ser reativado reemerge, causando a doença.

O herpes-zoster é causado pela reativação do VVZ latente na raiz dorsal e gânglios sensoriais dos indivíduos que apresentaram a infecção primária, a varicela de forma aparente ou subclínica. Essa reativação pode estar associada às condições de imunidade celular do indivíduo. A incidência do herpes-zoster aumenta com a idade porque a imunidade celular geral e específica contra o VVZ diminui com o envelhecimento, na presença de doença imunossupressiva, na infecção pelo o vírus da imunodeficiência humana, no uso de terapia imunossupressiva, particularmente radioterapia ou transplante de medula óssea, e também, seguindo-se a infecção primária intra-útero ou no início da infância, onde a resposta imune normal é diminuída. O contágio do herpes-zoster se dá, principalmente, pelo contacto direto com as vesículas infectadas, podendo ocasionar casos de varicela em indivíduos suscetíveis.

Em geral, não existe dificuldade no reconhecimento de formas típicas da varicela, particularmente se houver história de exposição. O diagnóstico pode ser mais difícil em pacientes imunocomprometidos, que podem apresentar quadros progressivos com envolvimento visceral. Casos modificados podem seguir-se à imunização passiva ou ativa, necessitando muitas vezes de confirmação laboratorial.
Correspondência para/ Correspondence to: Secretaria de Estado da Saúde de São Paulo

Av. Dr. Arnaldo, $3511^{\circ}$ andar sala 135

01246-901 São Paulo, SP, Brasil

E-mail: agencia@saude.sp.gov.br
*Texto de difusão técnico-científica da Secretaria de Estado da Saúde de São Paulo. Desenvolvido como parte do Programa de treinamento em epidemiologia aplicada aos serviços do Sistema Único de Saúde, promovido em parceria com a Faculdade de Saúde Pública da Universidade de São Paulo. 


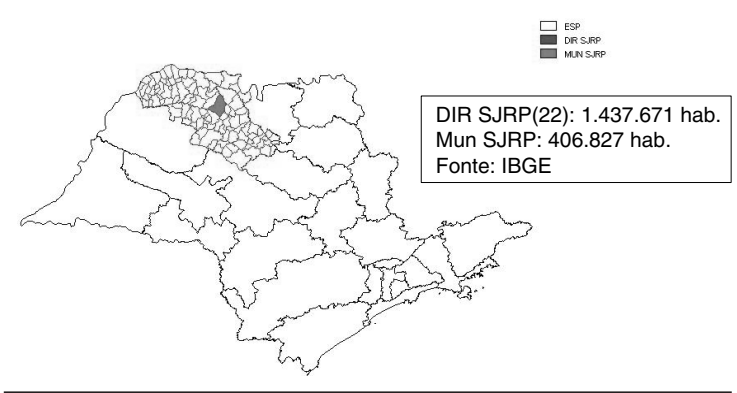

$\overline{\text { Figura } 1 \text { - Estado de São Paulo, DIR SJRP e município de }}$ São José do Rio Preto.

A varicela apresenta um custo social e econômico, mesmo considerando-se crianças previamente saudáveis, e não tanto relacionado à severidade da doença, mas principalmente devido à sua inevitabilidade. Estes custos incluem despesas médicas, como consultas, uso de terapêutica sintomática ou antiviral, hospitalizações devido a complicações e, principalmente, o ônus financeiro relacionado ao absenteísmo dos responsáveis pela criança, que necessita ser afastada da escola ou da creche e cuidada em nível domiciliar por um período em torno de cinco dias.

Em 1975, a vacina contra a varicela foi desenvolvida no Japão, a partir do VVZ atenuado, tornando possível a prevenção da infecção primária em crianças saudáveis. A vacina $\mathrm{Oka} / \mathrm{Biken}$ encontra-se licenciada para uso nessas crianças no Japão e Coréia, desde 1986 e 1988, respectivamente. A vacina Oka/Merck foi licenciada para uso em crianças saudáveis, adolescentes e adultos nos Estados Unidos, em 1995, assim como a Oka/RIT na Alemanha e Suécia.

Vários estudos demonstraram que a vacina é segura e imunogênica em crianças, adultos saudáveis e em pacientes imunocomprometidos. A vacina mostrou boa tolerabilidade, com poucas reações colaterais locais (vermelhidão e dor no local de aplicação). Estudos mostraram que a vacina tem eficácia em torno de $80 \%$ na proteção contra qualquer forma da doença e de $98 \%$ na prevenção de doença moderada ou severa. A análise dos custos e benefícios da vacinação contra varicela, de situações relacionadas à doença, como tratamento médico e perda de dias de trabalho pelos responsáveis, e também da incidência cumulativa da doença em longo prazo nas faixas etárias de risco mais elevadas, considerando-se a vacinação em idades precoces, mostrou ser ela custoefetiva, resultando em benefícios a sua inclusão em programas de vacinação rotineira.

Antes da ampla utilização da vacina, a varicela acometia aproximadamente quatro milhões de pessoas por ano nos Estados Unidos. Dados de vigilância de áre- as sentinelas mostram que, desde 1995, ocorre uma dramática redução da incidência da doença (em torno de $90 \%$ ) e da mortalidade (cerca de 66\%). A maior queda ocorreu no grupo alvo primário da vacinação, crianças de 1 a 4 anos de idade.

A varicela não é doença notificável no Brasil, tornando difícil a estimativa de sua prevalência em nosso meio. No entanto, os surtos da doença em creches, pré-escolas, escolas e comunidade em geral devem ser notificados ao Sistema Nacional de Agravos Notificáveis (Sinan).

A vacina contra varicela encontra-se disponível no Brasil desde 1998, nos Centros de Referência para Imnobiológicos Especiais (Cries), em três apresentações comerciais, todas elas utilizando a cepa japonesa original Oka.

No ano de 2003 foram notificados quase 60.000 casos de varicela no Estado de São Paulo, com um total de 60 óbitos. No mesmo ano, a Secretaria de Estado da Saúde de São Paulo incluiu a vacina contra a varicela como uma das medidas de controle deste agravo em creches, pois é sabido que nestes locais a incidência de varicela é maior do que em crianças da população em geral. Além disso, as manifestações clínicas nos casos secundários tendem a ser mais intensas do que no caso índice, com uma taxa de mortalidade mais elevada.

Em 2004, foram notificados 8.676 casos de varicela e até o final de maio de 2005 já foram contabilizados 613 casos no Estado, distribuídos na grande maioria das regionais de saúde.

No final de maio de 2005, a Secretaria de Saúde de São José do Rio Preto informou que o município evidenciou uma seqüência de surtos de varicela em creches e escolas localizadas em várias regiões da cidade.

São Paulo compõe-se de 24 regionais de saúde (DIR), estando a regional de São José do Rio Preto (SJRP) situada a noroeste do Estado, com 101 municípios em sua área de abrangência (Figura 1).

Na regional de São José do Rio Preto (DIR XXII) foram registrados 121,39 e 17 surtos em creches e escolas, nos anos de 2003, 2004 e 2005, respectivamente.

Para a investigação epidemiológica dos surtos, a DIR XXII e o município de São José do Rio Preto solicitaram à Divisão de Doenças de Transmissão Respiratória, do Centro de Vigilância Epidemiológica, da Secretaria de Estado da Saúde de São Paulo, a visita da equipe do EPISUS-SP, que se deslocou ao municí- 
pio entre 1 e 3 de junho de 2005, realizando a investigação em conjunto com as equipes da regional e municipal de vigilância epidemiológica.

Os principais objetivos da investigação foram:

- conhecer a situação clínica e epidemiológica de varicela da Regional XXII, em especial no município de São José do Rio Preto;

- investigar os casos confirmados de varicela através do Boletim de Notificação de Surtos e Ficha de Outros Agravos, realizando a busca ativa de casos por meio de visita às creches e escolas que notificaram surtos da doença no ano de 2005.

Caracteriza-se como surto a ocorrência de dois ou mais casos de varicela, confirmados clinicamente, restritos a um mesmo estabelecimento, num período menor do que quatro semanas. Vale ressaltar que a vacina está indicada em crianças de um a cinco anos que freqüentam creches e são suscetíveis à doença, a partir da ocorrência do primeiro caso, no período máximo de até quatro semanas do último caso.

Previamente à investigação de campo nas creches e/ ou escolas, foram realizadas reuniões com os grupos de vigilância epidemiológica da regional e do município, a fim de planejar a execução da investigação.

Quatorze estabelecimentos foram visitados, dentre os quais sete creches, cinco pré-escolas e duas escolas. Foram investigadas as crianças que freqüentavam as classes nas quais ocorreram casos de varicela, analisando-se os casos e não casos, a situação de suscetibilidade à doença, isto é, se já tiveram quadro de varicela no passado ou vacinação prévia. Outras variáveis também foram analisadas, tais como idade, sexo, bairro de moradia, período de permanência na creche, contato com outro caso confirmado na creche

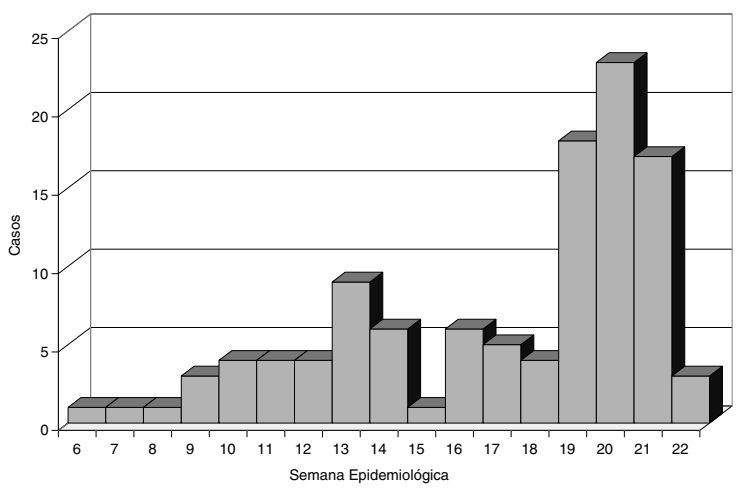

Figura 2 - Curva epidêmica dos casos de varicela relacionados a surtos em creches e escolas do Município de São José do Rio Preto, janeiro a maio de 2005 (até 31/5/05).

ou domicílio, hospitalização dos casos e medidas de controle no surto atual.

Foram identificados 118 casos, dos quais $77(65,3 \%)$ freqüentavam creches, $33(27,9 \%)$ pré-escolas e oito casos $(6,77 \%)$ freqüentavam o ensino fundamental em escolas. A taxa de ataque em cada estabelecimento está descrita na Tabela 1.

Os dados apresentados na Figura 2 referem-se aos surtos investigados em creches e pré-escolas. Nos 12 estabelecimentos investigados, o caso índice ocorreu em 6 de fevereiro e o último, 30 de maio de 2005. O pico da doença ocorreu entre as semanas epidemiológicas 19 a 21 , que correspondem ao período de 8 a 28 de maio de 2005. Sabe-se que a maior incidência desta doença ocorre ao final do inverno e início da primavera. Portanto, o pico observado pode significar a fase inicial da ascensão da incidência desse agravo em São José do Rio Preto, a depender da quantidade de suscetíveis. Apenas um caso foi hospitalizado, e não houve nenhum óbito.

Tabela 1 - Taxa de ataque de casos de varicela, segundo escolas e creches. Município de São José do Rio Preto, janeiro a maio de 2005 (até 31/5/05). [N=118, 14 estabelecimentos]

\begin{tabular}{|c|c|c|c|c|}
\hline Instituição/ Nome & Bairro & Casos & Total de alunos & Taxa de ataque $(\%)$ \\
\hline \multicolumn{5}{|l|}{ Creche } \\
\hline Tacla Said Beneti & Sto Antonio & 2 & 230 & 0,87 \\
\hline Gracia Maria S. Bortoleto & Eng Schmidt & 2 & 92 & 2,17 \\
\hline Maria Inês Arnal & João Paulo II & 4 & 166 & 2,41 \\
\hline Amor Sylvia Purita & Solo Sagrado & 6 & 161 & 3,73 \\
\hline Amélia Balbo Sacchetin & Jd Oliveiras & 12 & 235 & 5,11 \\
\hline Oswaldo de Carvalho & Jd Maria Lucia & 24 & 242 & 9,92 \\
\hline Caminho do Futuro & d Itapema & 27 & 176 & 15,34 \\
\hline \multicolumn{5}{|l|}{ Pré-escola } \\
\hline Pato Donald & Boa Vista & 3 & 229 & 1,31 \\
\hline Mônica e Cebolinha & Jd B Horizonte & 12 & 294 & 4,08 \\
\hline Dom Bosco & Cidade Nova & 3 & 66 & 4,55 \\
\hline Exata & Boa Vista & 2 & 40 & 5,00 \\
\hline Príncipe Encantado & $\mathrm{P}$ Industrial & 13 & 139 & 9,35 \\
\hline \multicolumn{5}{|l|}{ Escola } \\
\hline Padre Clemente Manton & Eng Schmidt & 2 & 850 & 0,24 \\
\hline Rui Nazaré & Jaguaré & 6 & 909 & 0,66 \\
\hline Total & & 118 & 3.829 & 3,08 \\
\hline
\end{tabular}

Fonte: Escolas e creches de São José do Rio Preto 
Tabela 2 - Resumo das variáveis analisadas em surtos de varicela em creches e escolas. Município de São José do Rio Preto, janeiro a maio de 2005 (até 31/5/05). [N=792, 12 estabelecimentos]

\begin{tabular}{|c|c|c|c|c|c|c|c|}
\hline Variáveis & $\begin{array}{l}\text { Idade } \\
\text { média } \\
\text { (anos) }\end{array}$ & $\begin{array}{l}\text { Idade } \\
\text { mediana } \\
\text { (anos) }\end{array}$ & $\begin{array}{l}\text { Variação } \\
\text { da idade } \\
\text { (anos) }\end{array}$ & $\begin{array}{c}\text { Sexo } \\
(\mathrm{N} \text { e } \%)\end{array}$ & $\begin{array}{l}\text { História } \\
\text { de contato } \\
(\mathrm{N} \mathrm{e} \mathrm{\% )}\end{array}$ & $\begin{array}{c}\text { Antecedente } \\
\text { de varicela } \\
(\mathrm{N} \text { e \%)* }\end{array}$ & $\begin{array}{c}\text { Vacinação } \\
\text { prévia } \\
(\mathrm{N} \text { e \%)** }\end{array}$ \\
\hline $\begin{array}{l}\text { Casos } \\
\mathrm{N}=110\end{array}$ & 2,85 & 2,00 & $0,5-7,0$ & $\begin{array}{c}\text { M: } 50(45,5 \%) \\
\text { F: } 60(54,5 \%)\end{array}$ & $\begin{array}{l}\text { Creche: } 93(84,5) \\
\text { Domicílio: } 2(1,81) \\
\text { Ignorado: } 15(13,6)\end{array}$ & $0(0,0)$ & $3(2,94)$ \\
\hline $\begin{array}{l}\text { Não casos } \\
\mathrm{N}=682\end{array}$ & 3,67 & 3,00 & $0,3-6,0$ & $\begin{array}{l}\text { M: } 362(53,1) \\
\text { F: } 320(46,9)\end{array}$ & $\begin{array}{c}\text { Creche: } 591(86,6) \\
\text { Domicílio: } 0(0)\end{array}$ & $122(22,4)$ & $54(9,39)$ \\
\hline
\end{tabular}

Fonte: Escolas e creches de São José do Rio Preto

* Excluídos 137 não-casos e 9 casos ignorados quanto ao antecedente de varicela

**Excluídos 107 não-casos e 8 casos ignorados quanto ao antecedente de vacinação prévia contra varicela

A média de idade dos casos foi de 2,85 anos, o que é estatisticamente diferente da média de idade entre os alunos que não desenvolveram varicela, que foi de 3,67 anos. As medianas foram 2,0 e 3,0 anos, entre casos e não casos, respectivamente.

Não houve predomínio da doença em nenhum dos gêneros.

Com relação à história de contato, 93 (84,5\%) dos casos tiveram contato com outros casos nas creches ou escolas; apenas dois foram identificados como casos secundários de casos índices domiciliares; e em 15 casos não foi possível conhecer a história de contato. Três casos de varicela tinham recebido vacinação prévia (um no ano de 2002 e dois em 2004).

Quatorze pacientes haviam recebido a vacina como medida de controle para o presente surto, o que não foi suficiente para abortar a doença. Nesses casos, o tempo médio entre a vacinação e o desenvolvimento da doença foi de 4,64 dias, com mediana de 4 dias.

A Academia Americana de Pediatria recomenda a administração da vacina contra a varicela em crianças suscetíveis dentro de 72 horas e, possivelmente, até 120 horas após a exposição à doença, para prevenir ou modificar o seu curso. Caso a exposição à doença não leve à infecção, a imunização pós-exposição deverá resultar em proteção contra exposição subseqüente. Algumas crianças que tenham sido expostas na mesma época do caso índice poderão não ser protegidas com a vacinação de bloqueio. Não há evidên- cias de que a vacina mencionada durante a fase présintomática ou prodrômica da doença aumente o risco de eventos adversos associados à vacina ou de uma doença natural mais grave.

Vale ressaltar que é muito difícil saber com precisão o exato momento da exposição à doença, principalmente num contexto de surto, em que várias crianças de uma mesma sala podem apresentar a doença em momentos diferentes, e a transmissão se inicia, por via respiratória, 1 a 2 dias antes do aparecimento do exantema, se estendendo enquanto houver vesículas. A varicela, sendo altamente contagiosa, se dissemina pelo contato direto pessoa a pessoa, por meio do exantema vesicular ativo ou de partículas aéreas (aerossóis) de secreções respiratórias transmitidas pelo ar (Tabela 2).

Em relação ao local de moradia, os alunos dos 12 estabelecimentos são provenientes de 90 bairros distintos, e os casos, moradores de 37 bairros, não apresentam nenhum padrão de concentração espacial, o que sustenta a hipótese de que a maioria dos casos tenha se exposto dentro das escolas e creches.

A descrição dessa investigação em creches e escolas do Município de São José do Rio Preto representa uma situação bastante comum no Estado de São Paulo, motivo pelo qual são tão discutidas as estratégias de imunoprofilaxia para a varicela, dentre outras medidas de controle, justificadas ainda pela possibilidade de uma evolução não satisfatória e taxas de mortalidade mais expressivas dos casos inseridos em contextos de surtos nesses estabelecimentos. 